\title{
Moving towards Preceptorship Model and Blended Learning Methodologies in Baccalaureate Nursing Education in Pakistan
}

\author{
Jacqueline Maria Dias, Zohra Kurji, Salima Gulamani, Yasmin Mithani \\ Aga Khan University School of Nursing and Midwifery, Karachi, Pakistan
}

\begin{abstract}
Clinical practice is the backbone of every nursing curriculum in which students experience application of theoretical concepts in the field sites to prepare them for their role and responsibilities in the community. In Pakistan, the preceptor-ship model will be applied for the first time for a course entitled "Advanced Concept of Community Health Nursing in the undergraduate Post RN BScN program (ACCHN)". Using a blended learning format this course used clinical placements both in Karachi and Hyderabad. The course had a blend of face to face and online components including: online modules, moderated discussion forums and activities, selfassessment quizzes, and podcasts. An exploratory qualitative study design was utilized by focus group discussions to appraise the effectiveness of the trio model used in this course by students, faculty as well as the preceptors, and to measure the outcome of the blended learning methodology. The key findings included preceptors where instrumental in facilitating clinical practicums and the move towards blended learning methodology was seen as an innovative teaching pedagogy by the faculty with the potential to improve learning. Students reported that utilization of preceptors allowed for deeper learning and preceptors should be allowed to grade a portion of the student assessment.
\end{abstract}

\section{Introduction}

Clinical practice is the backbone of every nursing curriculum in which students experience application of theoretical concepts in the field sites to prepare them for their role and responsibilities in the community [1]. In addition, student volumes are increasing day by day and to cater to these needs calls for innovation in clinical placements for the effective process of integration of theory into practice [1]. One way is the utilization of preceptors to facilitate clinical teaching. There are different models for clinical practice; faculty supervision and clinical/preceptor based model. Preceptor-ship model is as an effective teaching and learning strategy most frequently employed to educate undergraduate and graduate students in the practice settings [2].The preceptor-ship model is defined as "an individual teaching/ learning method in which each student is assigned to a particular preceptor so the nursing student can experience day to day practice with a role model and resource person immediately available within the clinical setting" [3].The literature defines the explicit role of preceptor as one who has a level of competence which facilitates student learning [4]. In addition, Budgen and Gamroth recommend that a preceptor needs to be competent, flexible and innovative with students [5]. According to Myrick, the key players of preceptor based model must have a mutual understanding of their roles and responsibility in order for everyone to fulfill their role [6].

\section{Literature Review}

The documented literature highlighted that use of preceptor based models provided a venue to integrate theory into practice. Nevertheless, there are various challenges which are highlighted with the preceptor based model, such as if a preceptor is not trained adequately the lack of competency may jeopardize student learning [7]. This challenge can be overcome by ensuring that trained preceptors with the requisite expertise are utilized. Only those potential preceptors who meet the course requirements should be utilized along with ongoing training [4].

Obtaining appropriate clinical sites is an ongoing challenge for faculty. According to literature, many nurse faculties have started utilizing a variety of clinical sites to expose students to different kinds of work settings to prepare them for their professional role and needs of the country [1]. Today, literature reiterates that a growing number of students are exposed to rural hospital under supervision of preceptors [6].The current Canadian preceptor based model concluded that each model has their conceptual and operational challenges such as uncertainty of the placement, lack of competency of preceptor, not letting out traditional practice and accepting synergy of innovation at practicum site which may threaten the students learning objectives as well as alter students' learning environment, 
ultimately declining the quality of preceptor based model [8].

In addition, today, the trend in pedagogy is a move away from the didactic way of teaching such as lectures, discussion, readings and a move to online learning which facilitates the use of preceptor models. [9]. The research findings of Zilembo and Monterosso interestingly pointed out that the preceptor role is considered as making or breaking of individual careers [10]. Many models and innovations can be implemented to improve student learning; however preceptor ship enable facilitation for nurses to grow professionally and build attributes like confidence and collaboration Studies indicated that preceptor based models increase knowledge and skills in students; if every individual in triad assumes their responsibilities [8, 10]. For example, student participates as active learner, preceptor as competent and experienced, and faculty as collaborator between two of them $[8,10]$.

In Pakistan the preceptor-ship model is an emerging model in one of the private universities of Karachi Pakistan, preceptor-ship model was applied first time for a course entitled "Advanced Concept of Community Health Nursing (ACCHN)" in the undergraduate Post RN BScN program. Using a blended learning format for the first time this course used clinical placements for student learning both in urban (Karachi) and semi urban (Hyderabad) areas via the use of preceptors. The clinical objectives are spelt out in Figure 1.

\footnotetext{
1. Analyze and demonstrated the role of a $\mathrm{CHN}$ in the Community

2. Apply the concepts of community participation and empowerment when addressing the specific health/developmental needs of the community

3. Conduct community assessment and diagnosis including the identification of high risk groups, utilizing

1. Gordon's Functional Health patterns and the principles of community participation

4. Collect, interpret, and apply statistics

5. Develop and implement action plan relevant to the community's need

6. Evaluate intervention strategies and modified the management plan accordingly

7. Participate in field team activities at the Primary Health Care (PHC)/ Family Health Centre (FHC)

8. Identify and utilize available resources and NGO's working with in the community, city, and country

9. Develop linkages between the PHC/FHC and the community, city and country for the sustainability purpose

10. Adapt nursing care documentation to the $\mathrm{PHC} / \mathrm{FHC}$ recordkeeping methods.

11. Complete a community health/development project based on the needs identified by the community.
}

Figure 1. Clinical Objectives of the Advance Concepts of Community Health Nursing (ACCHN)

\section{Methods}

In this section the study design will be discussed.

\subsection{Research Question}

The following two questions guided the study;

1. Explore the effectiveness of the preceptorship model in (ACCHN) course in the undergraduate program?

2. Describe advantages and disadvantages of using blended learning pedagogies in ACCHN course?

\subsection{Study Design}

An exploratory qualitative study design was used. The purpose of exploratory design is to study something which has been never explored [11]. In this study the researchers are searching for new knowledge, new insights, new understanding and new meaning. The preceptor-ship model has been introduced for the first time in ACCHN course in Pakistan; therefore, authors are contextually exploring its effectiveness, strength, challenges, advantages and disadvantages within Pakistan [12, $13]$.

\subsection{Study Sample}

Purposive sampling is utilized in this study. The goal of purposive sampling is to collect information specific cases [12]. The purposefully selected informants are the ones that are selected specifically to answer the research questions and that can benefit the study [13]. The reason for purposive sampling is to deliberately select the study participants to provide meaningful views of the desired perspective.

Efforts were made to obtain a representative heterogeneous sample of faculty, preceptors and students. The target population was four AKU SONAM faculties who taught in ACCHN course to year II Post RN BScN students in Karachi campus during the semester between January - May 2013. In addition, 09 students and 06 preceptors were interviewed through focus group discussions. The study was approved by the Aga Khan University ethics research committee (ERC). The financial support for this study came from a Blended Learning grant which was received by School of Nursing.

The interview guide for the focus group was developed by the researchers based on the literature review related to preceptor ship model. The interview guide was piloted on four students who were not participating in the study. The pilot testing 
ensured validity and reliability of interview tool. Additionally, it provided an opportunity to assess how well the participants understood the questions in the guide. Focus group discussions were conducted with the help of interview guide. The semi-structured interviews were used to collect the data. Each focus group lasted for approximately 45-60 minutes. In addition, student and preceptor evaluation forms were used to substantiate the data. Qualitative data from the focus group discussions was analyzed manually.

\section{Finding and Discussion}

In this section, findings from faculty, preceptor, and student will be explored. In addition, feedback of the use of blended pedagogies will be discussed.

\subsection{Findings from Faculty}

The key findings from faculty are that utilization of preceptors are indeed an innovative way of doing clinical. The preceptors provided opportunities for hands on experience to the students in the real setting. Additionally, students were involved in independent sustainable projects, as well received opportunities for participation in community partnerships with stakeholders. Faculty strongly felt that introductory workshop with the preceptor at beginning of the course was very helpful as they were given awareness about student objective and assessment criteria, and clinical expectation. However, faculty reported the need for ongoing preceptor ship training. Preceptors selected were highly experienced in their own clinical areas and communities. The salient feature according to faculty with regards to preceptorship model was rapport building in the community facilitated by the preceptors. However, faculty stressed that the preceptors needs to be involved in the grading and assessment of students clinical. With regards to limitations some of the preceptors had less qualification but they made it up by their years of experience. Similarly, Bilay and Mirick endorsed that this model has its limitation and difference of opinion and hesitation voiced up by academician such as lack of content expert, lack of acquaintance with curriculum as few of the major challenges of preceptor based model [2]. Manyon also echoed that preceptors need to be experienced, exhibit excellent listening skills and facilitate professional socialization among students [14]. Additionally, preceptor based models may fail if preceptors have time management issues, or lack knowledge and experience. Study emphasized that student learns a lot when preceptors are experienced [10].

\subsection{Findings from Preceptor}

The findings from the preceptors included a two way learning process. Some of the preceptors reported their own knowledge base increased. Also, due to their own work responsibilities they reported that at times student learning was compromised. The preceptors reported that they should be involved in the grading of the student. The preceptors added that the initial workshop was beneficial. However, they felt the need for ongoing training. Moreover, they also felt overwhelmed as student's theoretical knowledge was immense. However, reciprocally preceptors provided hand on experience in the clinical field.

While, describing the strengths of this preceptor model one of the major advantages was the active community participation in the entire project. The presence of the students was vivid as students engaged themselves in the community. Similarly Spouse 2011 also endorsed that effective training of preceptors needs to take place to ensure quality and bridge the theory practice gap [7]. Billay and Myrick 2008 also reiterate the need for ongoing training and continuous feedback for the sustainability of the preceptorship model to have better outcomes [2]. One major limitation pointed out by the preceptors was the time duration. The preceptors strongly felt if more time was allocated more sustainable results could have been achieved. Lastly, the preceptors felt challenged by the prevailing geo political conditions and so ensured students' safety by accompanying them or having a member of the health team present with students at all times in the community.

\subsection{Findings from Students}

The students reported that the preceptors are an invaluable resource, were helpful and facilitated their learning. They reported that the preceptors were the gatekeepers to the community. Students appreciated the preceptorship model as an innovative way of teaching pedagogy. However, students' reported the workload of the preceptors often resulted in a delay to provide students with ongoing feedback on their projects. Students felt they had made a substantial contribution to the community and had a sense of ownership via their clinical projects and community participation. Lastly, students learnt to take care of their personal and professional development needs as for the first time they got an opportunity to leave away from their homes. Students reported lack of logistic support which included transportation, electricity failure and bandwidth issues which at times comprised their learning. Student themselves are very apprehensive for the preceptor based model and literature suggest that the readiness of student is 
also very crucial. Researches have underscored that student preparedness increases their learning [10].

Another significant finding from this study is that communication is the back bone for this model. Therefore, it is imperative to keep communication channels open with students and preceptors via telephone, texting, and email. However, the limitation of this model, from student point of view, is that this model reduces faculty-student interaction. However, with integration of information technology, preceptor models with blended learning program are successful.

\subsection{Feedback about course}

This study also looked primarily at the course itself as the AACHN course was offered for the first time in a blended mode. The faculty reported the course website and the use of Moodle as a learning management system was friendly and easy to navigate. However, the online modules were lengthy and consumed a lot of time for marking discussion forums. Use of Wikis as a learning modality caused problems. To begin with if one student was using the Wiki other student could not participated at the same time. From the students' perspective they described the course as challenging and stimulating. They added the podcasts and story board were interesting blended teaching tools. In addition, the course objectives matched the course content and the assignments were pertinent and reflected the emphasis of the course. Students' reported both in the focus groups and in the student evaluation that faculty needed to provide more feedback to students on the discussion forums. Lastly, the comprehensive exam needed more structured guidelines. Additionally, preceptors needed to be given some percentage of the grading criteria.

\section{Recommendations}

The following recommendations arise from this study for the effectiveness of the preceptorship model:

1. Careful planning including administrative and financial support from the institution for travel and logistics to clinical placements along with accommodation and food.

2. The provision of IT for distance learning is mandatory.

3. Faculty time and energy and commitment are essential.

4. Preceptors need to be recognized.
5. Preceptors need to be given some percentage of the grading scheme

6. Wiki need to be replaced with Google docs.

7. Criteria for choosing a preceptor need to be established.

8. A data base for preceptors needs to be created for record keeping.

\section{Conclusion}

Based on the findings from this research study a curricular review has taken place at AKUSONAM in the Fall of 2013. The blended learning pedagogies have been incorporated into the Post RN Baccalaureate program curriculum. In addition, the use of preceptors has led to widespread utilization of preceptors along with ongoing training has been employed in other courses in baccalaureate program. A proposal for preceptors to grade students is under review. Criteria for choosing a preceptor along with minimum qualifications as well as number of students assigned to a preceptor have been established. These distinctive lessons are anticipated to go a long way in assisting programs and assisting blended learning courses in the developing world.

\section{Acknowledgement}

The researchers would like to acknowledge the blended learning grant received which enabled this study.

\section{References}

[1]. McKenna, L.G., Wellard, S.J. Discursive influences on clinical teaching in Australian undergraduate nursing programs. Nurse Education Today. 2004; 24:229-235.

[2]. Billay, D. and Myrick, F. (2008). Preceptorship: An integrative review of the literature. Nurse Education in Practice, 8, 258-266.

[3]. Chickerella, B. and Lutz, W. (1981). Professional nurturance: preceptorships for under graduate nursing students. American Journal of Nursing, 81, 107-109.

[4]. Brathwaite, A.C. and Lemonde, M. (2011). Team Preceptorship Model: A Solution for Students' Clinical Experience. International Scholarly Research Notices (ISRN Nursing), 1-7.

[5]. C. Budgen and L. Gamroth, "An overview of practice education models," Nurse Education Today, vol. 28, no. 3, pp. 273-283, 2008. View at Publisher - View at Google Scholar · View at Scopus.

[6]. Myrick $\mathrm{F}^{1}$, Yonge O, Billay D. Nurse Educ Pract. (2010) Mar; 10 (2):82-7. doi: 10.1016/j.nepr.2009.03.018. 
Epub 2009 May 12 Preceptorship and practical wisdom: A process of engaging in authentic nursing practice.

[7]. Spouse, J. (2001). Bridging theory and practice in the supervisory relationship: a sociocultural perspective. Journal of Advanced Nursing, 33(4), 512-522.

[8]. Sedgwick, M., \& Harris, S. (2012). A Critique of the Undergraduate Nursing Preceptorship Model. (L. Ferguson, Ed.) Nursing Research and Practice, 2012, 1-7.

[9]. Mitchell, D., \& Kennedy, M. (2013, January). The experience of undergraduate nursing students, preceptors and academic staff members in clinical practice: An exploration of this triadic relationship. New Zealand : Nelson Marlborough Institute of Technology.

[10]. Zilembo, M. and Monterosso, L. (2008). Towards a conceptual framework for preceptor ship in the clinical education of undergraduate nursing students. Contemporary Nurse: A Journal for the Australian Nursing Profession, 30 (1), 89-94.

[11]. Brink, P. M. (1998). Exploratory Designs. In P.J Brink. and M. J. Wood (Eds.), Advanced design in nursing research (pp.308-333). Thousand Oaks: Sage

[12]. Sandelowski, M. (2000). Whatever happened to qualitative description? Research in Nursing and Health, $23,334-340$.

[13]. Polit, D. F. and Beck, C. T. (2008). Nursing research: generating and assessing evidence for nursing practice. Philadelphia: Lippincott.

[14]. Manyon, A., Shipengrover, J., McGuigan, D., Haggerty, M., James, P., Danzo, A. Defining differences in the instructional styles of community preceptors. Medical Student Education. 2003; 35:181-186. 